
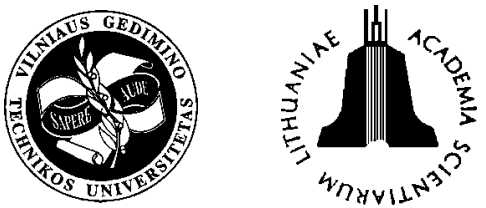

ISSN 1392-3730

JOURNAL OF CIVIL ENGINEERING AND MANAGEMENT

http:/www.vtu.lt/english/editions

2004, Vol X, No 3, 177-182

\title{
THE EFFECT OF MATERIAL STRENGTH ON THE BEHAVIOUR OF CONCRETE-FILLED STEEL ELEMENTS
}

\author{
Janis Brauns ${ }^{1}$, Karlis Rocens ${ }^{2}$ \\ ${ }^{1}$ Dept of Structural Engineering, Latvia University of Agriculture, Jelgava, 19 Academia St., LV-3001, Latvia. \\ E-mail: braun@latnet.lv 2Dept of Structural Engineering, Riga Technical University, Riga, 16 Azenes St., \\ LV-1048, Latvia. E-mail: rocensk@latnet.lv
}

Received 1 March 2004; accepted 14 May 2004

\begin{abstract}
Composite columns and beams are a combination of concrete and steel elements realising the advantages of both types of materials. According to codes for concrete-filled column, the plastic resistance of the cross-section is given as a sum of the components and taking into account the effect of confinement in case of circular sections. In this study the stress state in composite column is determined taking into account non-linear relationship of the modulus of elasticity and Poisson's ratio on the stress level in the concrete core. It has been determined that the effect of confinement occurs at a high stress level when structural steel acts in tension and concrete works in lateral compression. The stress state and load bearing capacity of section in bending is determined taking into account non-linear dependence on position of neutral axis. Because the ultimate limit state of material is not attained for all the parts simultaneously, to improve the stress state of a composite element and to prevent the possibility of a failure the appropriate strength of concrete and steel should be used. The safety of high-stressed composite structures can be achieved by using ultra-highperformance concrete (UHPC).
\end{abstract}

Keywords: composite columns and beams, stress state, non-linear deformation, ultra-high-performance concrete.

\section{Introduction}

Composite columns and beams, formed as hollow steel sections filled with concrete, have advantages in different architectural and structural solutions. The composite structure characterises with higher ductility than the concrete column and advantages of steel may be successfully used in connections. Concrete filling and reinforcing bars increase rigidity and load-bearing capacity of the hollow steel section with no changing in external dimensions of column. Filling improves the fire resistance as well. Composite column with a corresponding content of reinforcement can provide at least 90-minutes of fire-resistance rating [1].

According to EC4 [2], for determining the resistance of a section against bending moment, a full plastic stress distribution in the section has been assumed. The internal bending moment resulting from the stresses is the resistance of the section against acting moment. In order to increase the plastic bending capacity reinforcement can be included.

EC4 gives a simplified ultimate limit state design method for the composite structures, which is applicable for practical purposes. The method is based on consumption that ultimate strength of material is attained simultaneously in all parts of the section.
In previous decades investigations regarding interaction between steel shell and concrete core has been performed [3-7]. In general, it is concluded that for service load practically no bond exists and that the core and shell act as two independent materials. In the early stages of loading, the Poisson's ratio for concrete is lower than that for steel and the steel tube has no restraining effect on the concrete core. As the longitudinal strain increases, Poisson's ratio of concrete can remarkably increase. Therefore, the lateral expansion of unconstrained concrete gradually becomes greater than that of steel. A radial pressure develops at the steel-concrete interface thereby restraining the concrete core and setting up a hoop tension in the tube. At this stage, the concrete core is stressed triaxially and the steel tube biaxially. Interaction between steel tube and concrete is the key issue to understand the behaviour of this kind of column. It is shown [8] that concrete compaction affects the properties of the core and also may influence the interaction between the steel tube and its concrete core, and thus influences the behaviour of the composite columns.

The original contribution lies mainly in the use of concrete, especially UHPC, in the form of slender composite elements for bridges rather than massive elements more commonly associated with concrete structures [9-11]. 
In this study stress analysis of the composite column and beam is performed with the purpose to obtain the maximum value of load-bearing capacity and enhance the safety of the structure using components with the appropriate strength properties and taking into account the composite action. The effect of UHPC on the stress state and load-carrying capacity of composite elements is analysed.

\section{Analytical model for stress analysis}

The section presents a consideration on behaviour of short straight concrete-filled steel column under axial loading. The term "short column" refers to a compression member that can attain its ultimate capacity without overall buckling. Disregarding the local effects at the ends, the stress state in the cross-section of the middle part of the column is analysed. A reinforced concrete core with radius $R_{0}$ is included in steel tube of thickness $t$ (Fig 1). The reinforcement consists of symmetrically arranged longitudinal steel bars and circumferential reinforcing wire located at radius $R_{s}$ from axis $z$.

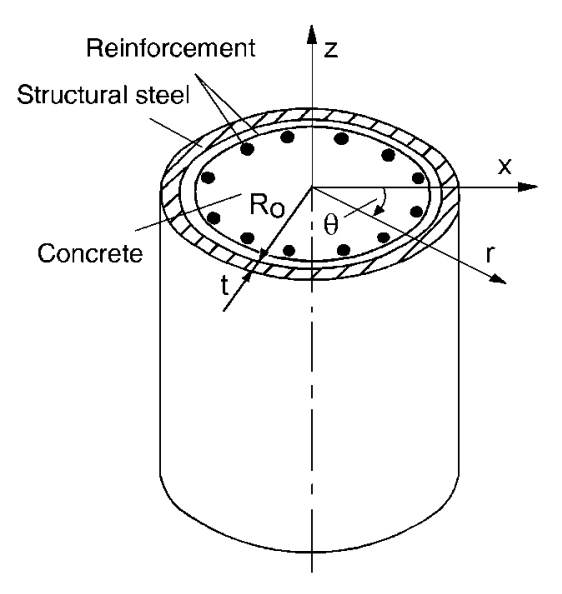

Fig 1. Concrete-filled hollow column with reinforcement

For radial displacements $w$ and circumferential displacements $u$ on the contact surface concrete-structural steel $\left(r=R_{0}\right)$ and concrete-reinforcement surface $\left(r=R_{S}\right)$ the following equalities are valid:

$$
\begin{aligned}
& w^{a}=w^{c} ; u^{a}=u^{c} ; \\
& w^{s}=w^{c} ; u^{s}=u^{c} .
\end{aligned}
$$

Here and below, the indices $a, c$ and $s$ refer to the steel tube, concrete and reinforcement. In the axial direction of the column, the cross-section area of the reinforcement is $A_{z}^{s}$, but in the circumferential direction $A_{\theta}^{s}$, placed with the given step. It is taken into account that the reinforcement is "spread" throughout the crosssectional area and, as a result, an anisotropic column is formed.
The following relationships should be written assuming throughout the steel tube an in-plane membrane stressed state:

$$
\begin{gathered}
\frac{\partial \sigma_{z}^{a}}{\partial z}=0 \\
\sigma_{\theta}^{a}=\frac{p_{c} R_{o}}{t}
\end{gathered}
$$

$$
\varepsilon_{z}^{a}=\frac{\partial w^{a}}{\partial z}=\mathrm{const} ; \varepsilon_{\theta}^{a}=\frac{u^{a}}{r},
$$

where $p_{c}$ - the contact pressure on the boundary surface of steel-tube concrete, $\sigma_{z}^{a}, \sigma_{\theta}^{a}, \varepsilon_{z}^{a}$ and $\varepsilon_{\theta}^{a}-$ stresses and strains of the steel tube in the axial and circumferential direction. The existing equality of stresses in the radial and circumferential direction $\left(\sigma_{r}^{c}=\sigma_{\theta}^{c}\right)$ in concrete core is assumed.

Taking into account the compatibility relationships (1) and (2), four equations can be written:

$$
\begin{gathered}
\frac{1}{E^{a}} \sigma_{z}^{a}-\frac{\nu^{a}}{E^{a}} \sigma_{\theta}^{a}=\frac{1}{E_{z}^{c}} \sigma_{z}^{c}-\frac{v_{z r}^{c}}{E_{r}^{c}} \sigma_{r}^{c}-\frac{v_{z \theta}^{c}}{E_{\theta}^{c}} \sigma_{\theta}^{c} \\
\frac{v^{a}}{E^{a}} \sigma_{z}^{a}-\frac{1}{E^{a}} \sigma_{\theta}^{a}=\frac{v_{z r}^{c}}{E_{z}^{c}} \sigma_{z}^{c}-\frac{1}{E_{r}^{c}} \sigma_{r}^{c}+\frac{v_{z \theta}^{c}}{E_{\theta}^{c}} \sigma_{\theta}^{c} ; \\
\frac{1}{E_{z}^{s}} \sigma_{z}^{s}=\frac{1}{E_{z}^{c}} \sigma_{z}^{c}-\frac{v_{z r}^{c}}{E_{r}^{c}} \sigma_{r}^{c}-\frac{v_{z \theta}^{c}}{E_{\theta}^{c}} \sigma_{\theta}^{c} ; \\
\frac{1}{E_{\theta}^{s}} \sigma_{\theta}^{s}=\frac{1}{E_{\theta}^{c}} \sigma_{\theta}^{c}-\frac{v_{r \theta}^{c}}{E_{r}^{c}} \sigma_{r}^{c}-\frac{v_{z \theta}^{c}}{E_{z}^{c}} \sigma_{z}^{c}
\end{gathered}
$$

were $v^{a}-$ is Poisson's ratio of the steel tube, $v_{i j}^{c}-$ Poisson's ratio values of the reinforced concrete $(i, j=r$, $z, \theta ; i \neq j)$. Equations (6) - (9) have been written taking into account the transverse deformation. The equilibrium equations in the $z$ and $\theta$ directions are as follows

$$
\begin{gathered}
\frac{A_{\theta}^{s}}{R_{s}} \sigma_{\theta}^{s}+\frac{t}{R_{0}} \sigma_{\theta}^{a}+\sigma_{\theta}^{c}=0 ; \\
A^{c} \sigma_{z}^{c}+A^{a} \sigma_{z}^{a}+A_{z}^{s}+q\left(A^{a}+A^{c}\right)=0,
\end{gathered}
$$

where $A^{c}$ and $A^{a}$ - the cross-sectional area of the concrete and structural steel accordingly, $E^{a}$ - modulus of elasticity of the steel tube, $E_{z}^{c}, E_{r}^{c}$ and $E_{\theta}^{c}-$ moduli of elasticity of the reinforced anisotropic concrete core in the directions $z, r$ and $\theta, E_{z}^{s}$ and $E_{\theta}^{s}$ - moduli of elasticity of the reinforcement in directions $z$ and $\theta, q-$ a uniformly distributed axial load. It is assumed the load is applied to the entire section.

The load-carrying capacity of composite elements in bending can be characterised by plastic deformation of structural steel in tension, by cracking of concrete in compression or by both. At the same time, the stresses 
in reinforcement can be more or less of the yield limit of steel. The stress analysis of composite elements in bending has been performed with certain assumptions: 1) the hypothesis of flat sections has been used; 2) the concrete lying in the tension zone of the section is assumed to be cracked and is therefore neglected; 3) the conditions of deformation continuity of structural steel and concrete fulfil in the compression zone; 4) relationship for the stress distribution in the compression zone of concrete has been assumed in the following non-linear form:

$$
\sigma_{z}^{c}=\sigma_{f}^{c}(z / x)^{n_{c}},
$$

where $\sigma_{z}^{c}$-stresses in concrete at distance $\mathrm{z}$ from neutral axis; $\sigma_{f}^{c}-$ stresses in concrete in more compressed fibre; $x$-depth of the compressed zone of concrete; $n_{c}-$ characteristic of the stress diagram form. The cross-section of reinforced composite beam and the stress-strain distribution diagrams are shown in Fig 2.
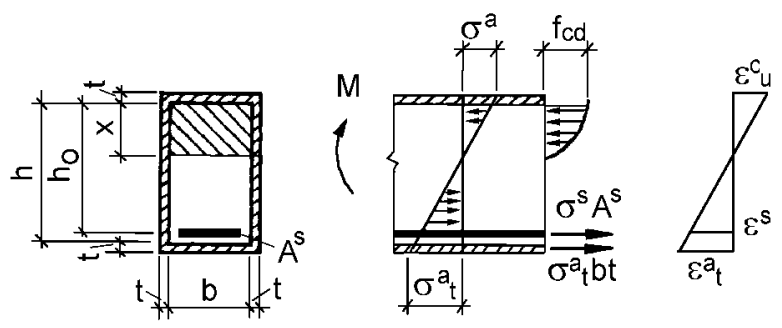

Fig 2. Stress and strain distribution in a composite beam

The characteristic $n_{c}$ can be determined in the following way

$$
n_{c}=1-\left(1-\frac{E_{u}^{c}}{E^{c}}\right)\left(\frac{\sigma_{f}^{c}}{f_{c}}\right)^{m},
$$

where experimental factor $m \cong 5,7 ; f_{c}$ - concrete strength.

Based on the equilibrium conditions of the internal forces and taking into account the hypothesis of flat sections, the position of neutral axis can be determined by using non-linear equation:

$$
\begin{aligned}
& x^{2}\left[\frac{f_{c d b}}{\left(1+E^{c}{ }_{u} / E^{c}\right) \varepsilon^{c}{ }_{u}}-2 t\left(E^{a}+E^{a}{ }_{t}\right)\right]+ \\
& x\left[E^{a}\left(-b t+2 h t-2 t^{2}\right)+E^{a}{ }_{t}\left(b t+4 h t+2 t^{2}\right)+E^{s} A^{s}\right]+ \\
& E^{a}\left(h b t+2 h t^{2}\right)-E^{a}{ }_{t}\left(h b t+2 h^{2} t+2 h t^{2}\right)- \\
& E^{s} A^{s} h_{0}=0,
\end{aligned}
$$

where $E^{c}{ }_{u}$ and $E^{c}$ - tangent and initial modulus of the concrete, $E^{a}{ }_{t}$ - modulus of constructional steel in tension, $\varepsilon_{u}^{c}$ - ultimate deformation of concrete in compression. The ultimate bending moment $M_{u}$ was determined by using the condition of equality of the moments in section of the beam

$$
\begin{aligned}
& M_{u}=b \int_{0}^{x} \sigma_{f}^{c}(z / x)^{n_{c}} z d z+\sigma^{a} b t x+ \\
& \frac{2}{3}\left[\sigma^{a} b t x(x+t)+\sigma_{t}^{a} t(h-x)(h+t-x)\right]+ \\
& \sigma^{s} A^{s}\left(h_{0}-x\right)+\sigma_{t}^{a} b t(h-x) .
\end{aligned}
$$

where $b, h$ and $h_{0}$ - width, height and effective height of concrete section.

\section{Numerical solution and analysis}

In order to perform the stress analysis in a composite column the system of six linear equations (6) - (11) was solved. In matrix form it is written as

$$
\text { [A] } \mathbf{X}=\mathbf{B} \text {. }
$$

The components of the unknown vector $\mathbf{X}$ are stresses in the steel tube, concrete, longitudinal and spiral reinforcement, ie,

$$
\mathbf{X}=\left[\sigma_{z}^{a}, \sigma_{\theta}^{a}, \sigma_{z}^{c}, \sigma_{\theta}^{c}, \sigma_{z}^{s}, \sigma_{\theta}^{s}\right]^{\mathrm{T}} .
$$

The matrix of system [A] and vector of constants $\mathbf{B}$ is determined from the stress-strain relationships and equilibrium equations as follows:

$$
\begin{aligned}
& \mathrm{A}=\left[\begin{array}{cccccc}
\frac{1}{E^{a}} & -\frac{v^{a}}{E^{a}} & -\frac{1}{E_{z}^{c}} & \frac{v_{z r}^{c}}{E_{r}^{c}}+\frac{v_{z \theta}^{c}}{E_{\theta}^{c}} & 0 & 0 \\
\frac{v^{a}}{E^{a}} & -\frac{1}{E^{a}} & -\frac{v_{r z}^{c}}{E_{z}^{c}} & \frac{1}{E_{r}^{c}}-\frac{v_{r \theta}^{c}}{E_{\theta}^{c}} & 0 & 0 \\
A^{a} & 0 & A^{c} & 0 & A_{z}^{s} & 0 \\
0 & 0 & \frac{1}{E_{z}^{c}} & -\left(\frac{v_{z r}^{c}}{E_{r}^{c}}+\frac{v_{r \theta}^{c}}{E_{\theta}^{c}}\right) & -\frac{1}{E_{z}^{s}} & 0 \\
0 & \frac{h}{R_{0}} & 0 & 1 & 0 & \frac{A_{\theta}^{s}}{R_{s}} \\
0 & 0 & -\frac{v_{z \theta}^{c}}{E_{z}^{c}} & -\frac{v_{r \theta}^{c}}{E_{r}^{c}}+\frac{1}{E_{\theta}^{c}} & 0 & -\frac{1}{E_{\theta}^{s}}
\end{array}\right] \\
& \mathbf{B}=\left[0,0,-q\left(A^{a}+A^{s}\right), 0,0,0\right]^{\mathrm{T}} .
\end{aligned}
$$

The following geometrical parameters were chosen for the analysis: diameter of circular hollow section $d=40,6 \mathrm{~cm}$, thickness of the steel tube section $t=0,88 \mathrm{~cm}$, reinforcement content $\mu=4 \%$ of the concrete section, distance from the central axis to the reinforcement bar axis $R_{s}=15,5 \mathrm{~cm}$, cross-sectional area of the longitudinal reinforcement $A_{z}^{s}=49 \mathrm{~cm}^{2}$ and secondary reinforcement $A_{\theta}{ }^{s}=0,1 \mathrm{~cm}^{2}$ (per $1 \mathrm{~cm}$ of the column length). The modulus of elasticity for the reinforcement is $E^{s}=200000 \mathrm{MPa}$, for structural steel $-E^{a}=$ $210000 \mathrm{MPa}$ and Poisson's ratio $v^{\mathrm{a}}=0,25$.

Concrete is a heterogeneous material because of its composite structure. Nevertheless, concrete is assumed homogeneous and the mechanical behaviour can be expressed in the form of stress-strain relationship. This relation is non-linear. However, with increasing compressive strength, the initial slope corresponding to the modu- 
lus of elasticity increases and the linear part extends to higher stress levels. Furthermore, the ultimate strain, ie the strain at maximum stress, increases with increasing compressive strength [9].

In order to determine real mechanical characteristics of concrete under compression stresses, prisms were tested for uniaxial compression. The development of axial strain $\sum_{a}$ and lateral strain $\varepsilon_{l}$ fixed in the test is shown in Fig 3. In the first part of the loading phase, the stressstrain relation shows an almost linear response. Due to the concrete heterogeneity, a uniform uniaxial stress applied to a concrete specimen obviously results in local non-uniformity. At a stress, corresponding approximately to $40 \%$ of the peak stress due to the difference in lateral deformation of material constituents, the stress-strain relation exhibits a visible non-linear response. Approximately at $85 \%$ of the peak stress, the response is marked non-linear.

In the initial stage of composite column loading, the Poisson's ratio of concrete core is lower than that of steel. Therefore, the steel tube expands faster in the radial direction compared with the concrete core; hence, the steel tube does not restrain the concrete core. As a result, columns centric loaded on the entire section are affected by the difference between the values of Poisson's ratio of the steel tube, $v^{a}$, and the concrete core, $v^{c}$.

In analysis the initial tangent modulus and tangent modulus at the given stress level have been used as the modulus of elasticity of the concrete. Based on experimental results, the Poisson's ratio of the concrete changes in accordance to the stress level, starting with $v^{c}=0,15$ in the initial stage [12]. The moduli of elasticity of a reinforced anisotropic concrete core $E_{z}^{c}, E_{r}^{c}$, and $E_{\theta}{ }^{c}$ as well as Poisson's ratio values $v_{i j}{ }^{c}$ were found on the basis of the reinforcement theory [13] taking into account the content of the reinforcement $\mu$ and mechanical properties of the constituents.

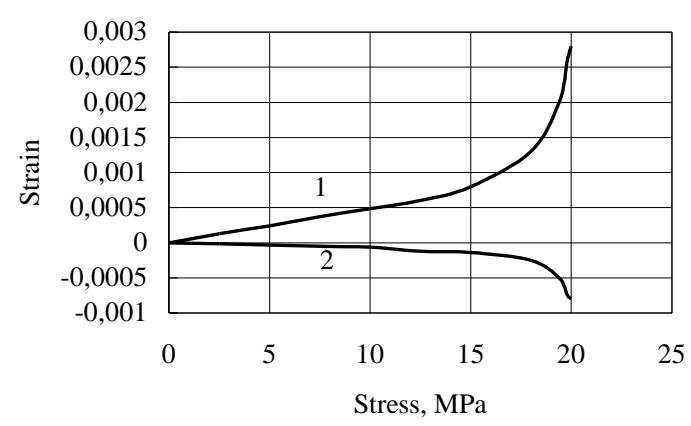

Fig 3. Stress-strain relation for concrete prism in uniaxial compression: $1-\Sigma_{a} ; 2-\Sigma_{l}$
The stresses in material components with applied force $N$ for conventional concrete and UHPC are given in Table 1. In the case of conventional concrete, stresses in steel section, concrete and reinforcement exceed the strength of materials. By using UHPC as column filling the load-carrying capacity keeps enough and stress level is satisfactory.

According to EC4, for the concrete-filled circular hollow sections, the load-bearing capacity of the concrete is increased due to the prevention of transverse strain. This effect is shown in Fig 4. The transverse compression of the concrete $\left(\sigma_{r}^{c}\right)$ at high stress levels leads to three-dimensional effects, which promotes the increase of the column resistance. At the same time, the circular tensile stresses $\left(\sigma_{\theta}{ }^{c}\right)$ arise on the cylindrical surfaces reducing its normal stress capacity.

Note that when axial stress in concrete is $\sigma_{z}^{c} \cong 0,85$ $f_{c k}$, the Poisson's ratio of concrete $v^{c}$ increases and becomes higher than that of the steel. In the region before fracture, the Poisson's ratio is approximately 0,3 [12]. Circular tensile stresses $\sigma_{\theta}^{c}$ in the concrete core of the column change into compression stresses due to the steel tube behaviour and the above-mentioned features of concrete deformation process.

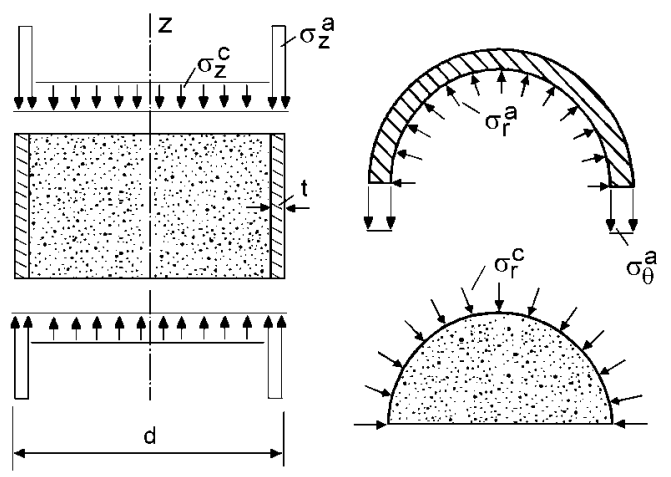

Fig 4. Stress distribution in the section of column

According to [2], the plastic resistance of the crosssection of a composite column with axial loading is given as the sum of the components:

$$
N_{p l . R d}=A^{a} f_{y d}+A^{c} f_{c d}+A_{z}^{s} f_{s d},
$$

where $A^{a}, A^{c}$ and $A_{z}^{s}$ are the cross-sectional areas of the structural steel, concrete and reinforcement in the axial direction, and $f_{y d}, f_{c d}$ and $f_{s d}$ are design strength values of the materials mentioned above.

Table 1. Stress values (MPa) in constituents of composite column for ratio $d / t=44$

\begin{tabular}{c|c|c|c|c|c|c|c}
\hline $\begin{array}{c}\text { Strength of } \\
\text { concrete, } \mathrm{MPa}\end{array}$ & $\begin{array}{c}\text { Axial force } N, \\
\mathrm{kN}\end{array}$ & $\sigma_{z}{ }^{a}$ & $\sigma_{\theta}{ }^{a}$ & $\sigma_{z}{ }^{c}$ & $\sigma_{z}{ }^{c}$ & $\sigma_{z}{ }^{s}$ & $\sigma_{\theta}{ }^{s}$ \\
\hline 30 & 3200 & -332 & $-4,3$ & -47 & $-0,1$ & -316 & 94 \\
\hline 180 & 3200 & -255 & $-2,0$ & -58 & $-0,2$ & -243 & 73 \\
\hline
\end{tabular}


By using the above-mentioned geometrical and mechanical properties of materials, steel grade Fe275 with characteristic yield strength $f_{y}=275 \mathrm{MPa}$, concrete of class $\mathrm{C} 30 / 37$ and relative slenderness ratio of column 0,15 the load-bearing capacity is $N_{p l . R d}=7162 \mathrm{kN}$. Taking into account the effect of confinement for circular hollow section, the load-bearing capacity increases and becomes $N_{p l . R d}=7935 \mathrm{kN}$. Here the analysis is performed using the secant modulus of concrete according to the strength class of the concrete. According to the results of stress analysis, the axial stresses in composite column core in case of conventional concrete are $\sigma_{z}^{c}>f_{c k}$, where $f_{c k}$ is the characteristic strength of concrete for the given strength class.

The analysis of the load-bearing capacity of the composite column is performed taking into account the design strength of steel and concrete as well as limit ratios of the circular hollow sections. Fig 5 shows that the first load limiting factors are concrete design strength $f_{c d}$ and diameter thickness ratio $d / t$. Using concrete of the strength class C35/45 and steel of grade Fe235 the load-bearing capacity of the composite column increases by $18 \%$ in comparison with concrete class $\mathrm{C} 30 / 37$. For a thin wall hollow section $(d / t=90)$ instead of section with $d / t=46$ the steel economy is $50 \%$.

The results of the stress analysis of the composite beam are shown in Fig 6. By using non-linear approach the position of neutral axis of reinforced concrete element depends on ultimate deformation of concrete in compression $\varepsilon^{c}{ }_{u}$. Taking into account this peculiarity, the stresses in structural steel $\sigma^{a}$ in tension zone approximately are equal to the yield limit $f_{y}$ (steel grade Fe235) when $\varepsilon^{c}{ }_{u}<1 \cdot 10^{-3}$. The ultimate bending moment $M_{u}$ in this case is by $40 \%$ less than plastic moment $M_{p l . R d}$ determined according to EC4. The comparison of composite beam load-bearing capacity in the case of conventional concrete and UHPC depending on ultimate compressive strain of concrete and compressive depth is given in Table 2.

Concrete filling leads to the increase of the loadbearing capacity that is much higher than that of steel elements and promotes the fire resistance as well. The concrete is contained within a circular steel profile and cannot split away, even if the ultimate strength of concrete is reached. Nevertheless, in order to prevent the possibility of a failure, especially, in the case of small

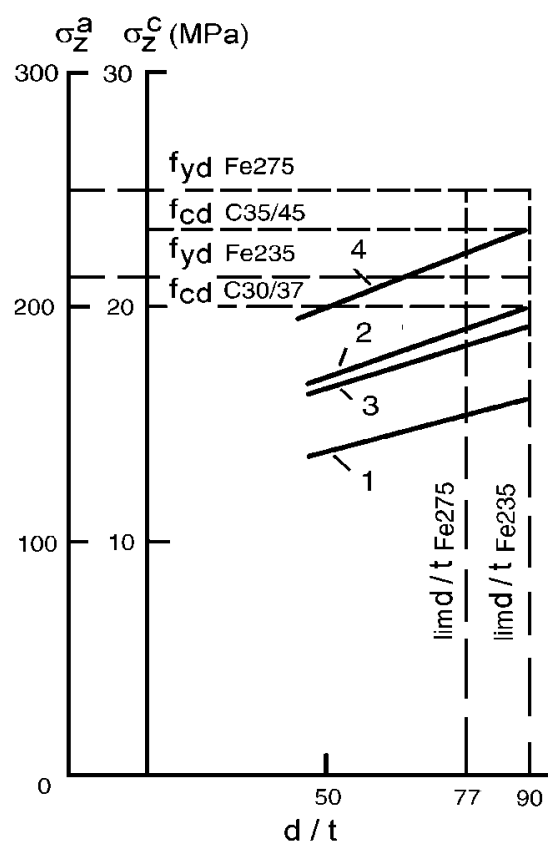

Fig 5. Variation of stresses in structural steel and concrete in relationship of ratio $d / t: 1,2-\sigma_{z}^{a}$ and $\sigma_{z}^{c}$ for axial force $N=4000 \mathrm{kN} ; 3,4-\sigma_{z}^{a}$ and $\sigma_{z}^{c}$ for $N=5000 \mathrm{kN}$

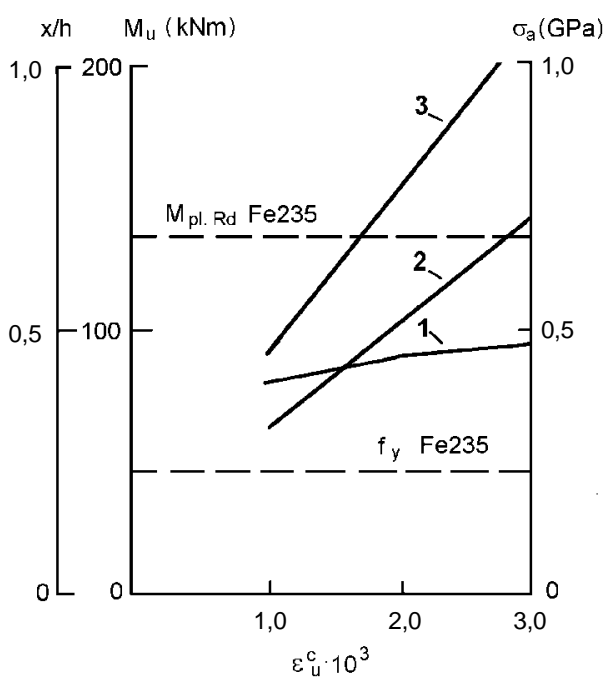

Fig 6. Influence of ultimate concrete deformation in compression on the position of neutral axis, stresses in structural steel and ultimate bending moment: $1-x / h, 2-\sigma^{a}$, $3-M_{u}$

Table 2. Comparison of composite beams with conventional concrete and UHPC

\begin{tabular}{c|c|c|c|c}
\hline \multirow{2}{*}{$\begin{array}{c}\text { Ultimate concrete } \\
\text { deformation, } \sum_{c u} \cdot 10^{3}\end{array}$} & \multicolumn{2}{|c}{ Compressive strength of concrete, MPa } \\
\cline { 2 - 5 } & $\begin{array}{c}\text { Relative } \\
\text { compressive depth, } \\
x / h\end{array}$ & $\begin{array}{c}\text { Ultimate moment } \\
M_{u}, \mathrm{kNm}\end{array}$ & $\begin{array}{c}\text { Relative } \\
\text { compressive depth, } \\
x / h\end{array}$ & $\begin{array}{c}\text { Ultimate moment } \\
M_{u}, \mathrm{kNm}\end{array}$ \\
\hline 1 & 0,42 & 92,7 & 0,27 & 186,8 \\
2 & 0,47 & 155,4 & 0,34 & 271,8 \\
3 & 0,49 & 248,0 & 0,39 & 383,4 \\
\hline
\end{tabular}


thickness of the structural steel and fire, the appropriate strength classes of concrete and steel have to be used. The effect depends on the type of concrete because the strength of core affects the point at which confinement can take place.

\section{Conclusions}

1. On the basis of constitutive relationships for material components, the stress state in a composite column is determined, taking into account the dependence of the modulus of elasticity and Poisson's ratio on the stress level in the concrete. It has been proved that the effect of confinement acts at a high stress level when the structural steel behaves in tension and the concrete in compression. The main load limiting factors are concrete design strength $f_{c d}$ and $d / t$ ratio. In the case of higher concrete strength class and steel grade Fe235 the load-bearing capacity of the composite column increases by $18 \%$. In the case of a thin hollow section $(d / t=90)$, the steel economy is for $50 \%$.

2. By using non-linear approach, the position of neutral axis of composite beam depends on the ultimate deformation of concrete in compression $\varepsilon^{c}{ }_{u}$. When $\varepsilon_{u}^{c}<1 \cdot 10^{-3}$ the ultimate bending moment $M_{u}$ is $40 \%$ less than plastic moment $M_{p l . R d}$ determined according to EC4 and the stresses in structural steel $\sigma^{a}{ }_{t}$ in tension zone are equal to yield limit $f_{y}$ (steel grade Fe235).

3 . The optimization of working conditions and crosssection area of the composite structure as well as the prevention of the possibility of a failure in the case of small thickness of structural steel and fire can be realized by using appropriate strength of concrete and steel. By using UHPC as steel element filling the increase of load carrying capacity can be significant.

\section{References}

1. Bergman, R.; Matsui, C.; Meinsma, C. \& Dutta, D. Design guide for concrete filled hollow section columns under static and seismic loading. Köln: Verlag TÜV Rheinland $\mathrm{GmbH}$, 1995. 68 p.

2. Eurocode 4: Design of composite steel and concrete structures, Part 1.1: General rules and rules for building. ENV 1994-1-1. 33 p.

3. Johansson, M. Composite action and confinement effects in tubular steel-concrete columns. Thesis for the degree of Doctor of Philosophy. Göteborg: Chalmers University of Technology, 2002. 77 p.

4. Kvedaras, A. K.; Šapalas, A. Research and practice of concrete-filled steel tubes in Lithuania. Journal of Structural Steel Research, Vol 49, No 2, 1999, p. 189-196.

5. Brauns, J. Analysis of stress state in concrete-filled steel column. Journal of Structural Steel Research, Vol 49, No 2, 1999, p. 197-212.

6. Lakshmi, B.; Shanmugan, N. E. Non-linear analysis of infilled steel-concrete composite columns. Journal of Structural Engineering, Vol 128, No 7, 2002, p. 922-933.

7. O'Shea, M. D.; Bridge, R. Q. Design of circular thin-walled concrete filled steel tubes. Journal of Structural Engineering, Vol 126, No 11, 2000, p. 1295-1303.

8. Han Lin-Hai H.; Guo-Huang, Y. Influence of concrete compaction on the strength of concrete-filled steel RHS columns. Journal of Structural Steel Research, Vol 59, No 6, 2003, p. 751-768.

9. Zilch, K.; Hennecke, M. Anwendung hochfesten Betons im Brückenbau, Forschungsbericht 99. Massivbau TUM. München, 1999.

10. Dowd, W. M.; Dauriac, Ch. E. Reactive powder concrete. The Construction Specifier, 48-52. 1996.

11. Ma, J.; Schneider, H. Properties of ultra-high-performance concrete. LACER, No 7, 25-32, 2002.

12. Neville, A. M. Properties of concrete, London: Pitman Publishing, 1981. 409 p.

13. Malmeister, A. K.; Tamuz, V. P. \& Teters G.A. Strength of polymer and composite materials (Сопротивление полимерных и композитных материалов). Riga: Zinatne, 1980. 571 p. (in Russian). 